\title{
Integration of Geometrical and Material Nonlinear Energy Sink with Piezoelectric Material Energy Harvester
}

\author{
Ye-Wei Zhang, ${ }^{1,2}$ Chuang Wang, ${ }^{1}$ Bin Yuan, ${ }^{1}$ and Bo Fang ${ }^{1}$ \\ ${ }^{1}$ Faculty of Aerospace Engineering, Shenyang Aerospace University, Shenyang 110136, China \\ ${ }^{2}$ State Key Laboratory of Structural Analysis for Industrial Equipment, Dalian University of Technology, Dalian 116024, China \\ Correspondence should be addressed to Ye-Wei Zhang; zhangyewei1218@126.com
}

Received 12 January 2017; Revised 6 March 2017; Accepted 15 March 2017; Published 28 March 2017

Academic Editor: Mohammad Amin Hariri-Ardebili

Copyright (C) 2017 Ye-Wei Zhang et al. This is an open access article distributed under the Creative Commons Attribution License, which permits unrestricted use, distribution, and reproduction in any medium, provided the original work is properly cited.

\begin{abstract}
This paper presents a novel design by integrating geometrical and material nonlinear energy sink (NES) with a piezoelectric-based vibration energy harvester under shock excitation, which can realize vibration control and energy harvesting. The nonlinear spring and hysteresis behavior of the NES could reflect geometrical and material nonlinearity, respectively. Two configurations of the piezoelectric device, including the piezoelectric element embedded between the NES mass and the single-degree-of-freedom system or ground, are utilised to examine the energy dissipated by damper and hysteresis behavior of NES and the energy harvested by the piezoelectric element. Similar numerical research methods of Runge-Kutta algorithm are used to investigate the two configurations. The energy transaction measure (ETM) is adopted to examine the instantaneous energy transaction between the primary and the NES-piezoelectricity system. And it demonstrates that the dissipated and harvested energy transaction is transferred from the primary system to the NES-piezoelectricity system and the instantaneous transaction of mechanical energy occupies a major part of the energy of transaction. Both figurations could realize vibration control efficiently.
\end{abstract}

\section{Introduction}

A nonlinear energy sink (NES) is a simple single or multidegrees of freedom (MDOF) system, and it can dissipate primary system energy and realize vibration control through the use of a damper and a nonlinear stiffness spring. Extensive studies have investigated some methods to reveal the capability of NES and passively control the system [1-4]. Zhang et al. analysed the effectiveness of NES connected to an axially moving string and proved that NES can effectively suppress the vibration of the axially moving string with transverse wind loadings [5]. Starosvetsky and Gendelman studied a two-DOF system with NES in the resonance and proved that simultaneous targeted energy transfer from linear oscillator to a NES is feasible [6]. Yang et al. conducted a numerical study on a pipe-NES system and found that the system can efficiently transfer and dissipate the vibration energy generated by fluid movement in the pipe [7]. Luongo and Zulli considered a general, nonlinear, multiDOF structure attached to a nonlinear oscillator with small mass and damping, and a mixed multiple scale/harmonic balance method was proposed to obtain differential equations describing the slow- and fast-flow dynamics of the entire structure [8]. Zhang et al. analysed the influence of flexible solar arrays on the passive multistrut vibration isolation platform of control moment gyroscopes for a satellite and discussed the reasonable parameters of flexible solar arrays [9]. Fang et al. presented an approach by integrating NES with giant magnetostrictive material (GMM) to realize vibration mitigation and energy harvesting. Parametric optimization was made to check how the values of NES mass, stiffness, and damper affect the performance of the integration of a NES and a GMM harvester [10]. Ebrahimzade et al. studied the performance of linear passive vibration absorbers and nonlinear passive vibration absorbers or nonlinear energy sink (NES) on the stability properties and nonlinear behaviors of an aeroelastic model [11].

The energy of vibration dissipated by a NES damper could be very large in several cases that make energy harvesting economically efficient. Given that a piezoelectric material can 
convert mechanical vibration into electrical energy with a simple structure, piezoelectric energy harvesting is considered as a self-power source in wireless sensor network systems [12]. Jacquelin et al. designed a piezoelectric harvester to harvest impact energy and discovered the influence of several mechanical parameters on harvesting output energy in order to optimize its performance [13]. Renno et al. presented a study of the effects of damping and electromechanical coupling on the power optimality of vibration energy harvesting. It is shown that mechanical dampers have an effect on optimal frequency ratios and optimal harvested power [14]. NES can absorb and dissipate energy through targeted energy transfers (TET) so that NES coupled with piezoelectric element could realize vibration control and energy harvesting. Ahmadabadi and Khadem utilised two configurations composed of NES and a piezoelectric element for vibration mitigation of a freefree beam subjected to shock excitation [15], and the NES they mentioned did not possess material nonlinearity which could realize vibration mitigation. Zhang et al. presented a piezoelectric energy harvesting device based on NES to achieve simultaneous broadband energy harvesting. The study shows that the apparatus has similar characteristics as NES as follows: 1:1 resonance, targeted energy transfer, and so forth [16].

In most cases, the actual behaviors of structures are not linear; these structures can present nonlinear behaviors in general and nonsmooth or hysteresis ones in particular (e.g., hysteresis behavior of magnetorheological fluid dampers and shape-memory alloys) [17]. The nonlinear and hysteresis behaviors of structures need to be studied to thoroughly understand the real responses of structures under external excitations. The Bouc-Wen model was proposed to describe the complex nonlinear characteristics of hysteretic systems $[18,19]$. Ikhouane et al. performed an analytical study on how the parameters of the Bouc-Wen model influence the shape of the hysteresis loop, and some specific features of the hysteresis loop are defined formally [20]. Charalampakis comprehensively examined the response and dissipated energy of the Bouc-Wen model. New analytical and numerical solutions were derived through a generic model formulation without any parameter constraints [21]. Lamarque and Savadkoohi investigated time multiscale energy exchange between a main system which is of Bouc-Wen family models of hysteresis and a cubic NES, and application of the coupled NES in passive control of a main system with hysteresis behavior was demonstrated [22]. Savadkoohi et al. presented a general methodology to deal with time evolutionary energy exchanges between two oscillators with dual nonlinearities: a NES with smooth nonlinear geometrical (cubic) and nonsmooth hysteresis (Bouc-Wen) behaviors [23]. Based on the geometrical NES with material nonlinearity and the configurations composed of NES and a piezoelectric element [15], the research is made as follows.

The present study investigates a system comprised of geometrical NES with hysteresis behavior reflecting material nonlinearity and a piezoelectricity-based vibration energy harvester, which is attached to the single-degree-of-freedom primary system under shock excitation. Two configurations of the piezoelectric device, including the piezoelectric

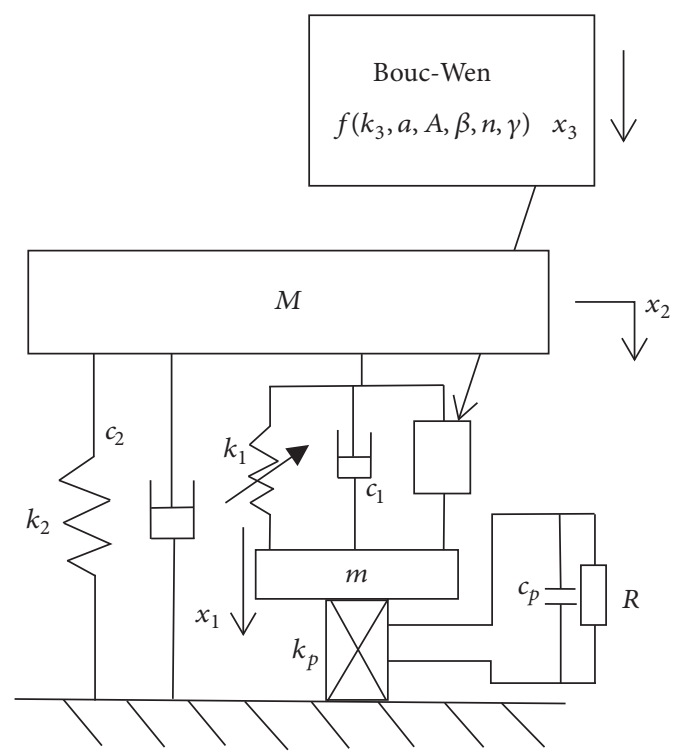

FIGURE 1: The single-degree-of-freedom system with the NES-piezoelectricity system: configuration 1 .

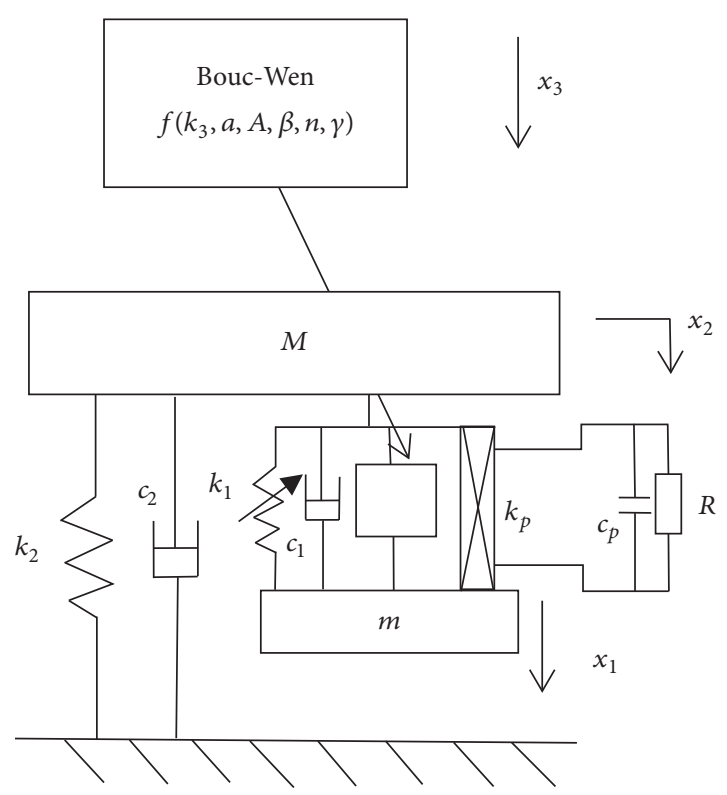

FIGURE 2: The single-degree-of-freedom system with NES-piezoelectricity system: configuration 2 .

element embedded between the NES mass and the structure or ground, are studied through similar methods. The energy transaction measure (ETM) is adopted to study the instantaneous energy transaction between the primary and the NESpiezoelectricity system.

\section{Configuration Models}

Figures 1 and 2 show the primary hysteresis system containing NES and a piezoelectric element. Figure 1 shows that the piezoelectric element is in the inset between the NES mass 
and ground. Figure 2 shows that the piezoelectric element is embedded between the NES mass and the primary system.

Mass $M$ is subjected to an external shock load, $F(t)$ [15], which can be expressed in the following form:

$$
F(t)=A_{1} \cdot H\left(\frac{T}{8}-t\right) \cdot \sin \left(\frac{2 \pi t}{T}\right),
$$

where $A_{1}=8 \times 10^{3}, H$ means Heaviside function, $T=0.5 / \pi$. The dynamic equations of motion of the two configurations are given in the following forms.

\section{Configuration 1}

$$
\begin{aligned}
& m \ddot{x}_{1}+c_{1}\left(\dot{x}_{1}-\dot{x}_{2}\right)+k_{1}\left(x_{1}-x_{2}\right)^{3}+a k_{3}\left(x_{1}-x_{2}\right) \\
& \quad+(1-a) k_{3}\left(x_{3}-x_{2}\right)+k_{p} x_{1}+\theta V=0, \\
& M \ddot{x}_{2}+c_{1}\left(\dot{x}_{2}-\dot{x}_{1}\right)+k_{1}\left(x_{2}-x_{1}\right)^{3}+c_{2} \dot{x}_{2} \\
& \quad+a k_{3}\left(x_{2}-x_{1}\right)+(1-a) k_{3}\left(x_{2}-x_{3}\right) \\
& \quad+k_{2} x_{2}=F(t), \\
& \dot{x}_{3}-A \dot{x}_{1}+\beta\left|\dot{x}_{1}\right|\left|x_{3}\right|^{n-1} x_{3}+\gamma \dot{x}_{1}\left|x_{3}\right|^{n}=0, \\
& c_{p} \dot{V}+\frac{V}{R}-\theta \dot{x}_{1}=0 .
\end{aligned}
$$

\section{Configuration 2}

$$
\begin{aligned}
& m \ddot{x}_{1}+c_{1}\left(\dot{x}_{1}-\dot{x}_{2}\right)+k_{1}\left(x_{1}-x_{2}\right)^{3}+a k_{3}\left(x_{1}-x_{2}\right) \\
& \quad+(1-a) k_{3}\left(x_{3}-x_{2}\right)+k_{p}\left(x_{1}-x_{2}\right)+\theta V=0, \\
& M \ddot{x}_{2}+c_{1}\left(\dot{x}_{2}-\dot{x}_{1}\right)+k_{1}\left(x_{2}-x_{1}\right)^{3}+c_{2} \dot{x}_{2} \\
& \quad+a k_{3}\left(x_{2}-x_{1}\right)+(1-a) k_{3}\left(x_{2}-x_{3}\right)+k_{2} x_{2} \\
& \quad+k_{p}\left(x_{2}-x_{1}\right)-\theta V=F(t), \\
& \dot{x}_{3}-A \dot{x}_{1}+\beta\left|\dot{x}_{1}\right|\left|x_{3}\right|^{n-1} x_{3}+\gamma \dot{x}_{1}\left|x_{3}\right|^{n}=0, \\
& c_{p} \dot{V}+\frac{V}{R}-\theta\left(\dot{x}_{1}-\dot{x}_{2}\right)=0,
\end{aligned}
$$

where $M$ and $m$ are the rigid mass and NES mass, respectively; $x_{1}, x_{2}$, and $x_{3}$ are the displacements of the NES mass, the rigid mass, and the internal variable of the hysteresis model, respectively, which are all relative to the ground; $c_{1}$ and $c_{2}$ are the linear damping coefficients; $k_{2}$ is the linear spring stiffness; $k_{1}$ is the cubic nonlinear spring stiffness; $k_{p}$ and $c_{p}$ are the linear equivalent stiffness and clamped capacitance of the piezoelectric element, respectively; $R$ is the external resistance; $V$ is the voltage across the electrodes of the piezoelectric element; and $\theta$ is the electromechanical coupling coefficient. The hysteresis behavior is assumed to be of Bouc-Wen type, $f\left(a, k_{3}, A, \beta, n, \gamma\right)$, with the following characteristics: $x_{3}$ is the internal variable of the hysteresis model, $k_{2}$ is the initial linear stiffness, the postyield stiffness is $K_{p}, a=K_{p} / k_{2}$ is the ratio of the postyield stiffness $\left(K_{p}\right)$ to the initial stiffness, $A, \beta>0$, and $\gamma$ and $n$ are dimensionless Bouc-Wen parameters controlling the model behavior.

The parameters of the system are $m=7 \mathrm{~kg}, M=60 \mathrm{~kg}$, $k_{2}=2.1346 * 10^{6} \mathrm{~N} / \mathrm{m}$, and $c_{2}=10 \mathrm{Ns} / \mathrm{m}[10]$. The parameters of the piezoelectric device are as follows: $k_{p}=10^{3} \mathrm{~N} / \mathrm{m}$, $R=8.2 * 10^{5} \Omega, c_{p}=10^{(-8)} \mathrm{F}$, and $\theta=0.002 \mathrm{C} / \mathrm{m}^{2}$ [24]. The parameters of the hysteresis model are as follows: $k_{3}=$ $5000 \mathrm{~N} / \mathrm{m}, A=1, a=0.5, \beta=0.3 \mathrm{~m}^{-2}, \gamma=0.7 \mathrm{~m}^{-2}$, and $n=1$ [25]. In the following numerical simulations, the initial values are given for a better energy harvesting performance: $x_{1}, x_{2}, x_{3}$, and the time derivative of $x_{2}$ and $x_{3}$ are zero, while the time derivative of $x_{1}$ equals $0.4 \mathrm{~m} / \mathrm{s}$.

\section{Methodologies and Simulations}

Runge-Kutta algorithm (ode45 function of Matlab) [26, 27] is used to investigate the nonlinear energy dissipated by the NES damper and hysteresis behavior and harvested by the piezoelectric device. The final calculation results must satisfy the relation provided in (2) and (3) to ensure that the calculation of the model is sufficiently accurate.

$$
\begin{aligned}
& E_{\text {out }}(t)=\left[\frac{1}{2} m \dot{x}_{1}^{2}+\frac{1}{2} M \dot{x}_{2}^{2}\right]+\left[\frac{1}{4} k_{1}\left(x_{1}-x_{2}\right)^{4}\right. \\
& \left.+\frac{1}{2} k_{2} x_{2}^{2}+\frac{1}{2} k_{p} w^{2}+\frac{1}{2} c_{p} V^{2}+\frac{1}{2} a k_{3}\left(x_{1}-x_{2}\right)^{2}\right] \\
& +\left[\int_{0}^{t} c_{1}\left(\dot{x}_{1}-\dot{x}_{2}\right)^{2} d t+\int_{0}^{t} c_{2} \dot{x}_{2}^{2} d t\right. \\
& \left.+E_{\text {dissipation,hysteretic }}(t)\right]+E_{\text {harvest }}(t), \\
& E_{\text {in }}(t)=\int_{0}^{t} F(\tau) \dot{x}_{2}(\tau) d \tau \\
& E_{\text {harvest }}(t)=\int_{0}^{t} \frac{V^{2}}{R} d t .
\end{aligned}
$$

Equation (7) derives from (5) and (6) as follows:

$$
\eta_{\text {harvest,piezo }}(t)=\frac{E_{\text {harvest }}(t)}{E_{\text {in }}(t)} \times 100,
$$

where $E_{\text {in }}(t)$ and $E_{\text {out }}(t)$ are the input and output energy up to time $t, E_{\text {harvest }}(t)$ is the harvested energy by the piezoelectric device, $\eta_{\text {harvest,piezo }}(t)$ is percentage of the transient excitation energy dissipated by the piezoelectric device, and $w$ is the piezoelectric element displacement and defined by

$$
\begin{aligned}
& w=x_{1} \quad \text { for configuration } 1, \\
& w=x_{1}-x_{2} \quad \text { for configuration } 2
\end{aligned}
$$

The influence of spring stiffness and damper of NES on the percentage of harvested energy by the piezoelectric device is described by Figure 3 .

In Figure 3, different values of the spring stiffness and the damper of NES are considered for both configurations, namely, $k_{1} \in\left[10,10^{9}\right]$ and $c_{1} \in[10,170]$. In the region of $k_{1} \in$ 


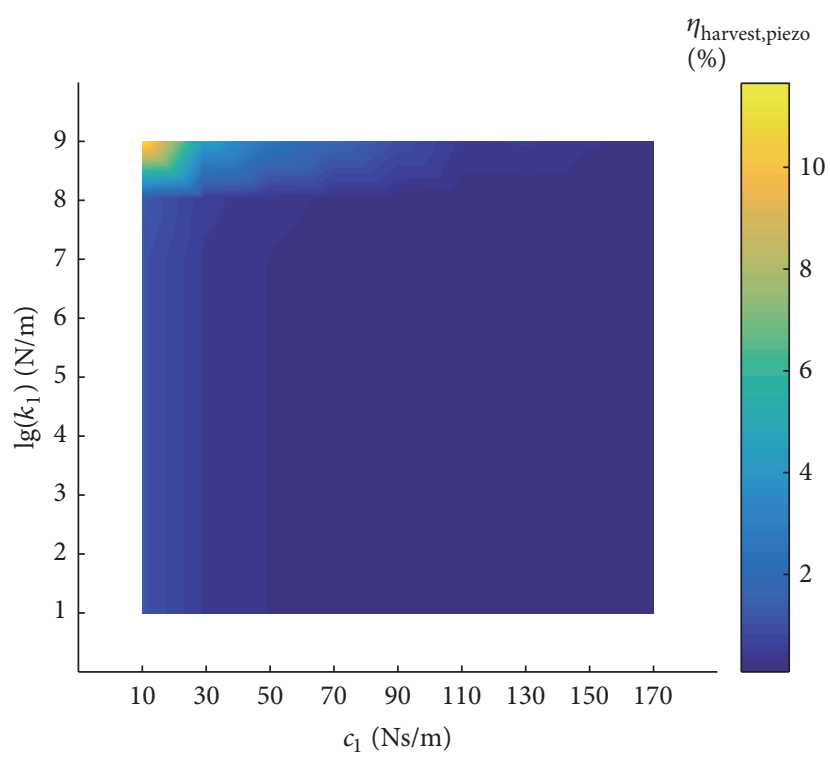

(a)

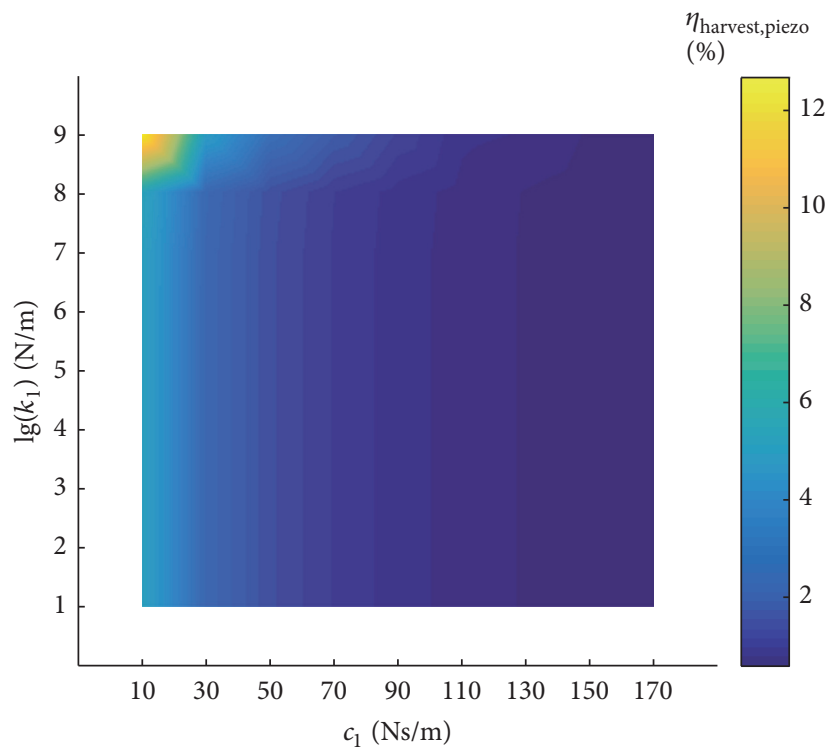

(c)

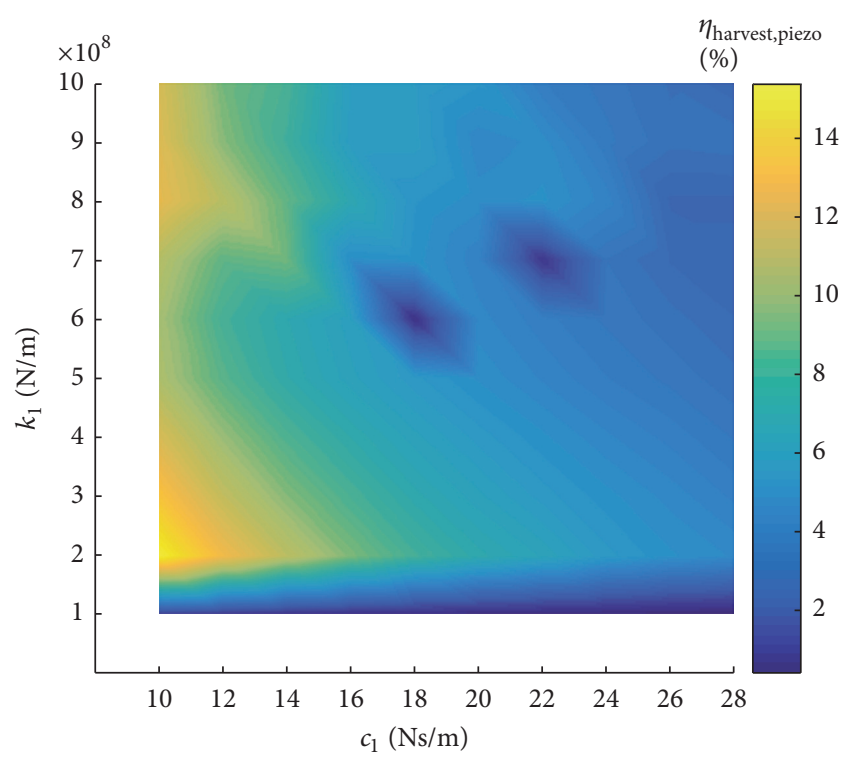

(b)

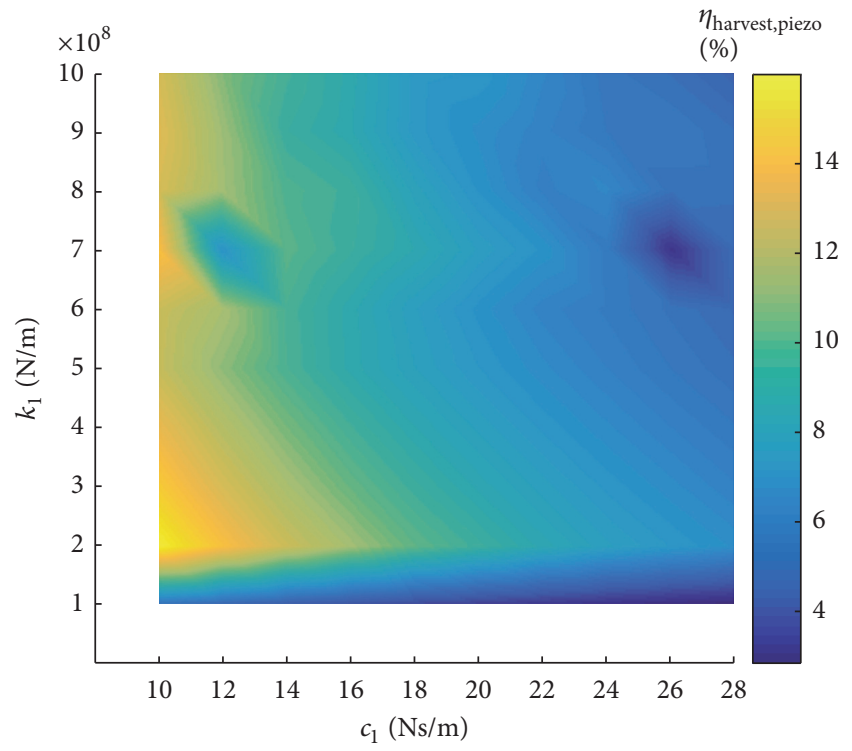

(d)

FIGURE 3: (a) The percentage of energy harvested by the piezoelectric device and (b) its enlargement of configuration 1. (c) The percentage of energy harvested by the piezoelectric device and (d) its enlargement of configuration 2.

$\left[10^{8}, 10^{9}\right]$ and $c_{1} \in[10,20], \eta_{\text {harvest,piezo }}$ is obviously higher than others. The spring stiffness $k_{1}$ has no effect on $\eta_{\text {harvest,piezo }}$ except for the distinct boundary when $k_{1}$ is about $10^{8} \mathrm{~N} / \mathrm{m}$, while the damper $c_{1}$ is positively correlated with $\eta_{\text {harvest,piezo }}$ in both configurations.

Input energy is dissipated by the NES damper and the hysteresis behavior of the Bouc-Wen model and harvested by the piezoelectric device. The percentage of the transient excitation energy dissipated by the NES damper $\left(\eta_{\text {damp,NES }}\right)$ and hysteresis behavior ( $\left.\eta_{\text {dissipation,hysteretic }}\right)$ and harvested by the piezoelectric device ( $\left.\eta_{\text {harvest,piezo }}\right)$ is expressed in (9), (11), and (7), respectively. In consideration of improving energy harvesting, the NES damper was selected with a relative small parameter, namely, $c_{1}=10 \mathrm{Ns} / \mathrm{m}$.

$$
\eta_{\text {damp,NES }}(t)=\frac{\int_{0}^{t} c_{1}\left[\dot{x}_{1}(\tau)-\dot{x}_{2}(\tau)\right] d \tau}{E_{\text {in }}} \times 100 .
$$

From (4), the equation below could be derived:

$$
\begin{gathered}
E_{\text {dissipation,hysteretic }}(t)=E_{\text {in }}(t)-\left[\frac{1}{2} m \dot{x}_{1}{ }^{2}+\frac{1}{2} M \dot{x}_{2}{ }^{2}\right] \\
-\left[\frac{1}{4} k_{1}\left(x_{1}-x_{2}\right)^{4}+\frac{1}{2} k_{2} x_{2}{ }^{2}+\frac{1}{2} k_{p} w^{2}+\frac{1}{2} c_{p} V^{2}\right.
\end{gathered}
$$




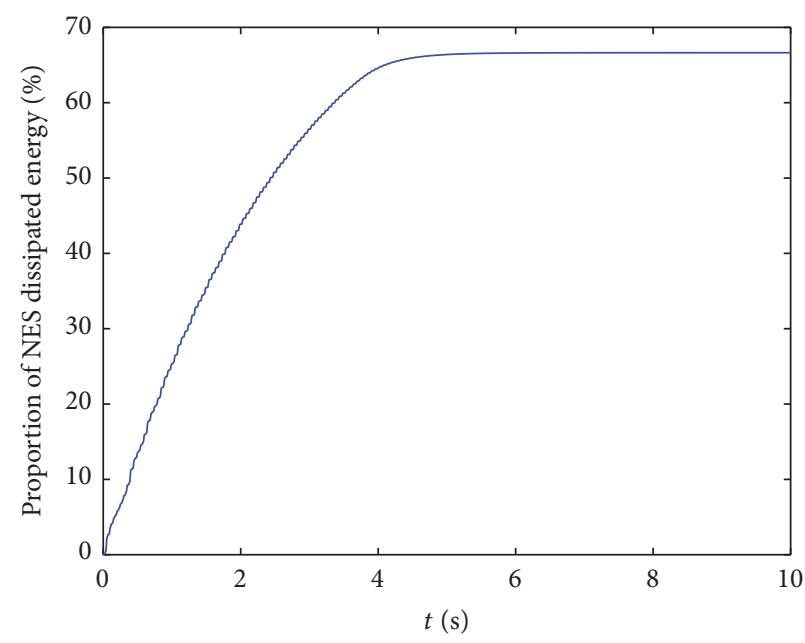

(a)

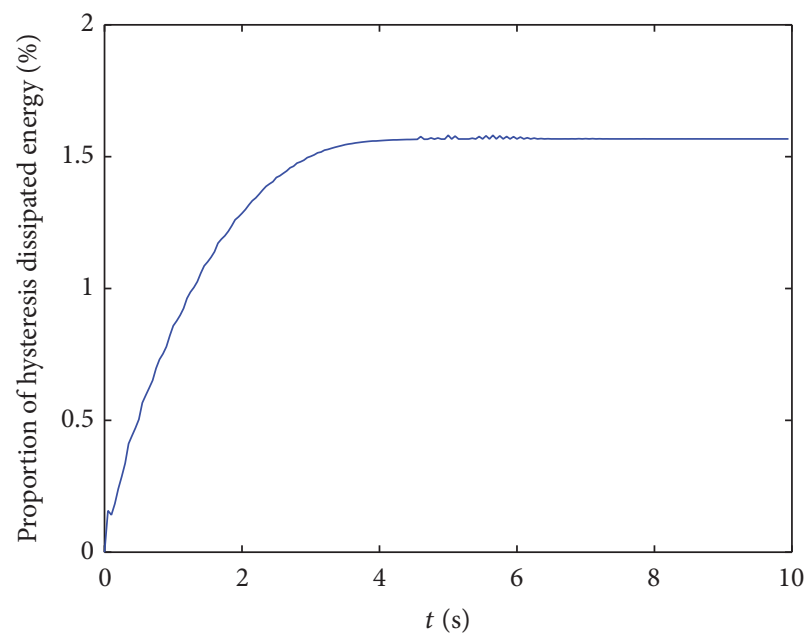

(b)

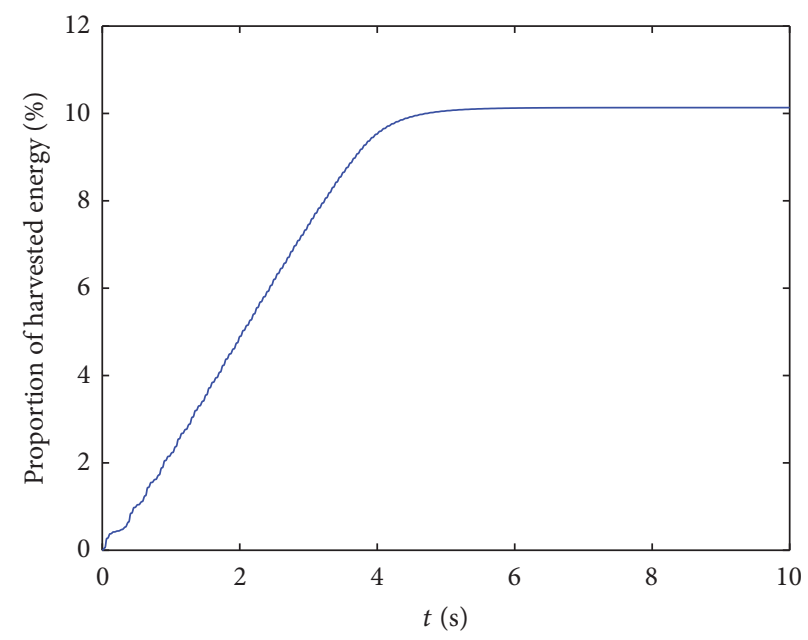

(c)

FIGURE 4: Configuration 1: (a) the percentage of energy dissipated by the NES damper; (b) the percentage of energy dissipated by the hysteresis behavior; (c) the percentage of energy harvested by the piezoelectric device.

$$
\begin{aligned}
& \left.+\frac{1}{2} a k_{3}\left(x_{1}-x_{2}\right)^{2}\right]-\left[\int_{0}^{t} c_{1}\left(\dot{x}_{1}-\dot{x}_{2}\right)^{2} d t\right. \\
& \left.+\int_{0}^{t} c_{2} \dot{x}_{2}^{2} d t\right]-E_{\text {harvest }}(t), \\
& \eta_{\text {dissipation,hysteretic }}(t)=\frac{E_{\text {dissipation,hysteretic }}}{E_{\text {in }}} \times 100 .
\end{aligned}
$$

Figures 4 and $5(\mathrm{a})-5(\mathrm{c})$ show the percentage of the captured energy dissipated by the NES damper and hysteresis behavior and harvested by the piezoelectric device, respectively. The curves in Figures 4 and 5(b) are fitted so that the tendency of energy dissipated by hysteresis behavior could be analysed better. Figures 4 and 5 show that the system vibration ceased in 4th second approximately. The captured shock energy dissipated by the NES damper and hysteresis behavior and harvested by the piezoelectric element amounts to about $66.63 \%, 10.13 \%$, and $1.57 \%$ for configuration 1, respectively, while it is $64.28 \%, 12.10 \%$, and $3.17 \%$ for configuration 2 . This phenomenon illustrates that most of the vibratory energy is dissipated by the NES damper and harvested by the piezoelectric material, and a small part of the energy is dissipated by the hysteresis behavior. The values of dissipated and harvested energy by NESpiezoelectric system of the two configurations are quite close. If both configurations are feasible, configuration 2 is given the priority to be adopted because of the higher energy harvesting.

The expression of instantaneous energy is presented below to show the energy change in the NES-piezoelectricity systems under external excitation. 


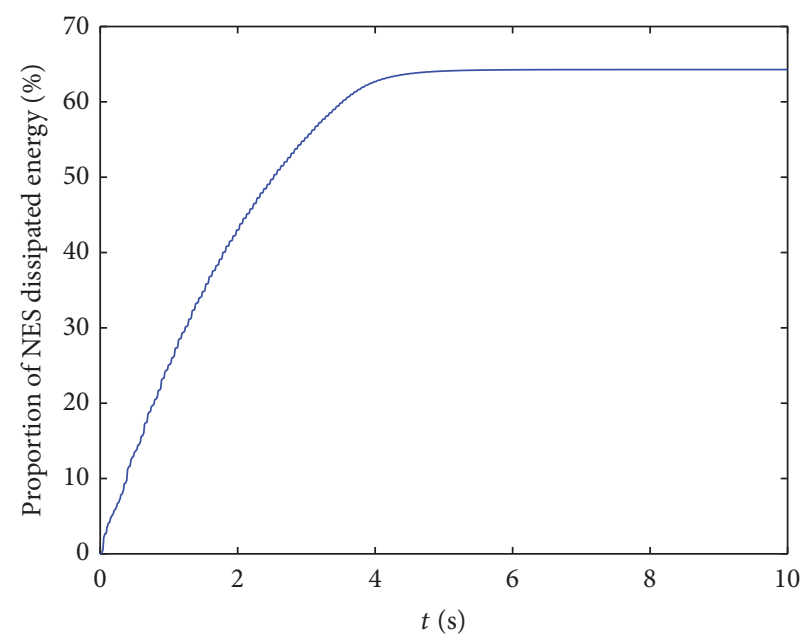

(a)

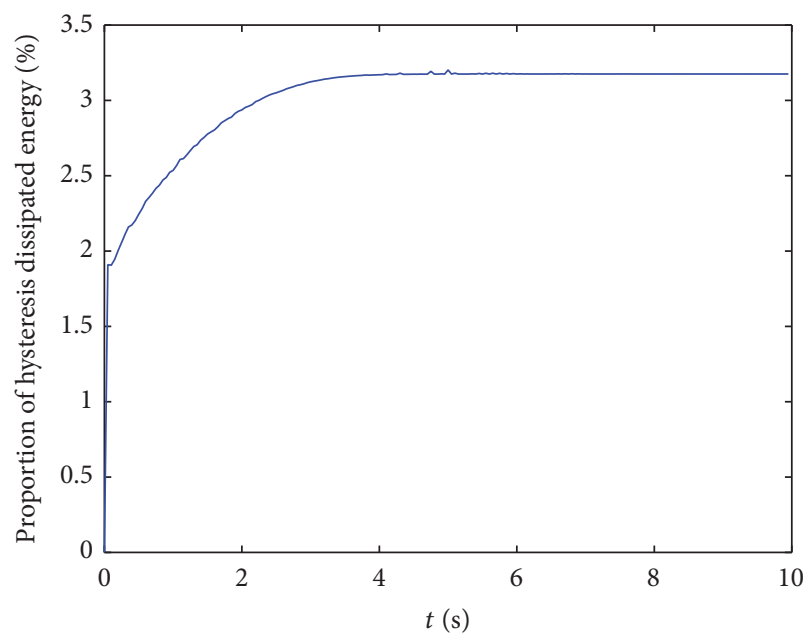

(b)

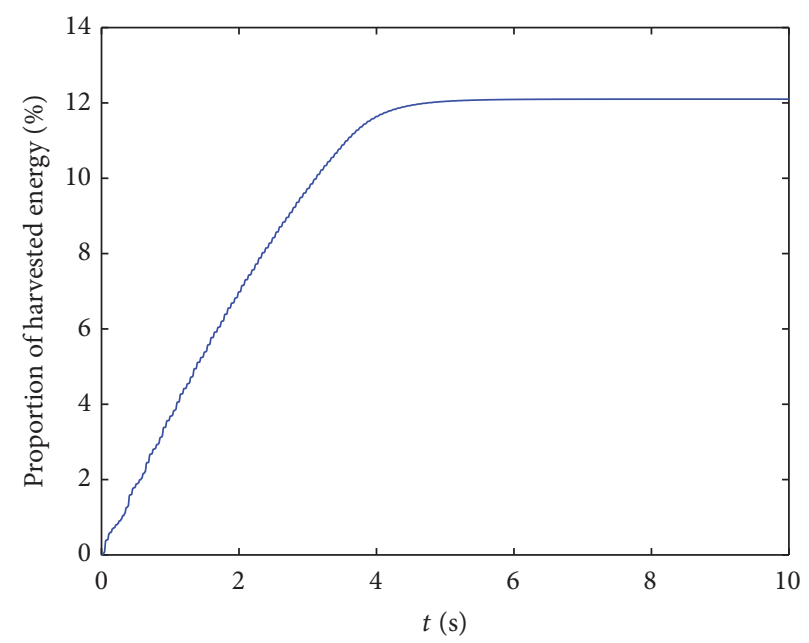

(c)

FIGURE 5: Configuration 2: (a) the percentage of energy dissipated by the NES damper; (b) the percentage of energy dissipated by the hysteresis behavior; (c) the percentage of energy harvested by the piezoelectric device.

$$
\begin{aligned}
\eta_{\text {NES,piezo,hysteretic }}(t) & =\frac{E_{\text {kinetic }}(t)+E_{\text {potential }}(t)+E_{\text {potential,hysteretic }}(t)}{E_{\text {in }}} \\
& =\frac{(1 / 2) m \dot{x}_{1}^{2}(t)+(1 / 4) k_{1}\left[x_{1}(t)-x_{2}(t)\right]^{4}+(1 / 2) k_{p}\left[x_{1}(t)-x_{2}(t)\right]^{2}+(1 / 2) a k_{3}\left(x_{1}-x_{2}\right)^{2}}{\int_{0}^{t} F(\tau) \dot{x}_{2}(\tau) d \tau},
\end{aligned}
$$

where $E_{\text {kinetic }}(t)$ is the instantaneous kinetic energy, $E_{\text {potential }}(t)$ is the instantaneous elastic potential energy included in NES and the piezoelectric element, and $E_{\text {potential,hysteretic }}(t)$ is the instantaneous elastic potential energy of the Bouc-Wen model. For both configurations, Figure 6 shows variation of the percentage of the instantaneous input energy captured in the NES-piezoelectricity system with different spring stiffness of NES as time goes on. The value of spring stiffness has no obvious correlation with the proportion of instantaneous input energy. And the instantaneous mechanical energy approaches 0 as time passes.

The energy transaction measure (ETM) tremendously contributes to investigating the energy exchange [28], so it 


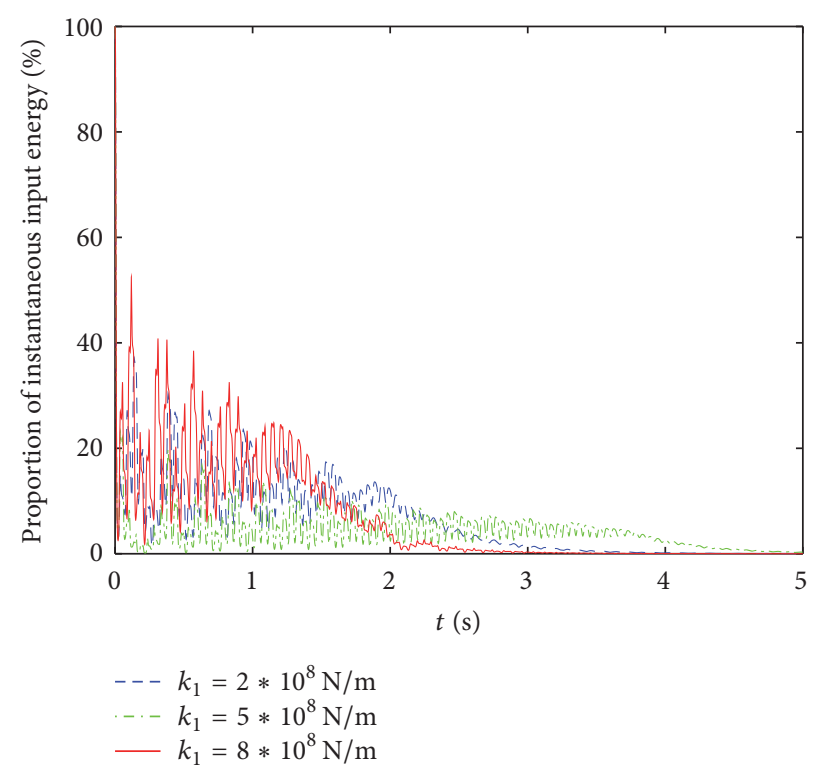

(a)

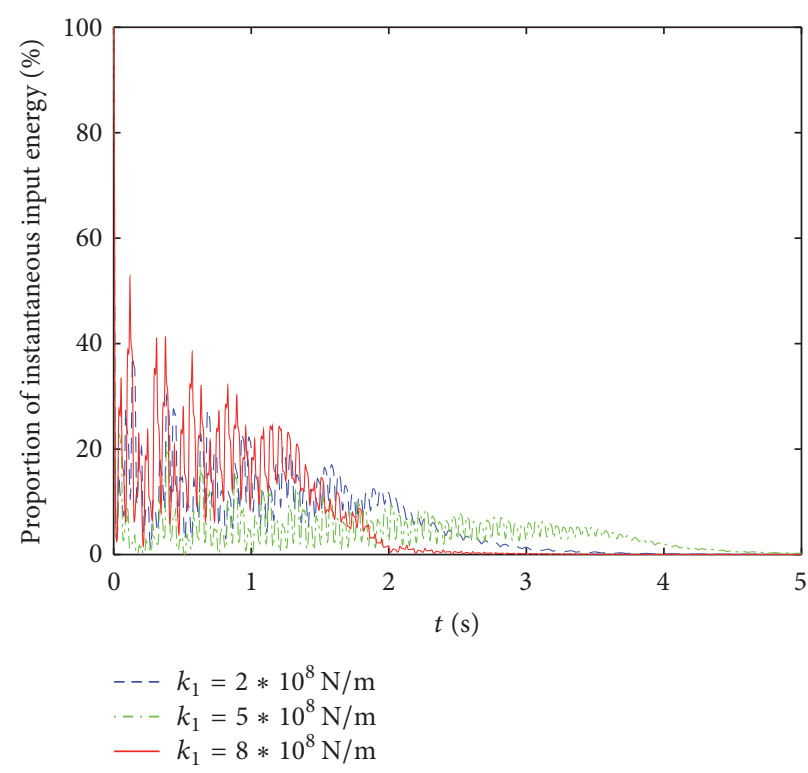

(c)

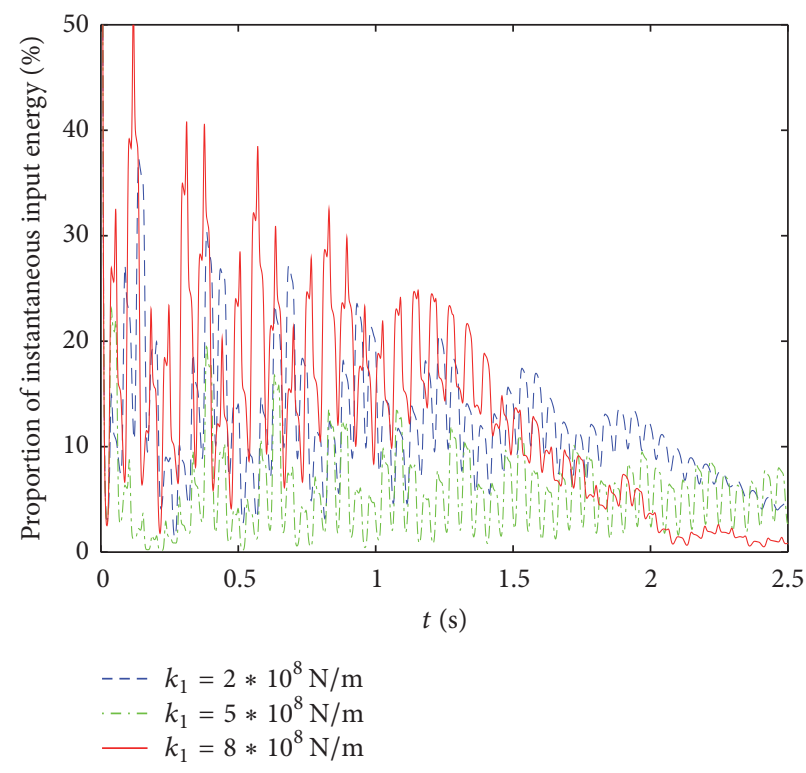

(b)

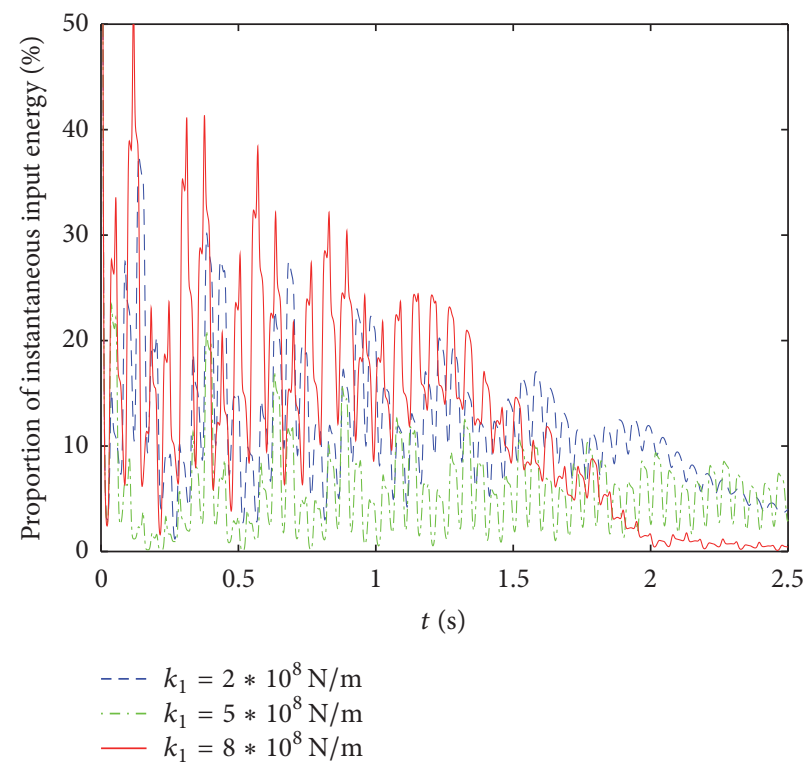

(d)

FIGURE 6: (a) The proportion of instantaneous input energy and (b) its enlargement of configuration 1; (c) the proportion of instantaneous input energy and (d) its enlargement of configuration 2.

is adopted to study the instantaneous energy transaction between the primary and NES-piezoelectricity system in this paper. ETM, $E_{\text {Trans }}$, between the two subsystems is defined in

$$
\begin{aligned}
E_{\text {Trans }}= & \Delta E_{\text {kinetic,NES }}+\Delta E_{\text {potential,NES }}+\Delta E_{\text {damp,NES }} \\
& +\Delta E_{\text {potential,hysteretic }}+\Delta E_{\text {dissipation,hysteretic }} \\
& +\Delta E_{\text {potential,piezo }}+\Delta E_{\text {harvest,piezo }},
\end{aligned}
$$

where $\Delta$ represents the corresponding energy difference value among the subsystems. For instant, with time $t$, $E_{\text {kinetic,NES }}(t)=(1 / 2) m \dot{x}_{1}^{2}(t)$ is the kinetic energy in the NES;
$E_{\text {potential,NES }}=(1 / 4) k_{1}\left[x_{1}(t)-x_{2}(t)\right]^{4}$ is the elastic potential energy in NES; $E_{\text {damp }, \mathrm{NES}}=\int_{0}^{t} c_{1}\left[\dot{x}_{1}(\tau)-\dot{x}_{2}(\tau)\right]^{2} d \tau$ is the dissipated energy up to time $t$ by NES, while $E_{\text {potential,hysteretic }}=$ $(1 / 2) a k_{3}\left[x_{1}(t)-x_{2}(t)\right]^{2}$ is the elastic potential energy of hysteresis behavior; $E_{\text {potential,piezo }}=(1 / 2) k_{p}\left[x_{1}(t)-x_{2}(t)\right]^{2}$ is the elastic potential energy in the piezoelectric device. ETM is favourable to the identification of the transient energy inflow or outflow between the primary and NESpiezoelectricity system. Positive ETM values indicate that the transient energy is transferred from the primary system to the NES-piezoelectricity system. Negative ETM values that indicate transient energy are transferred from 


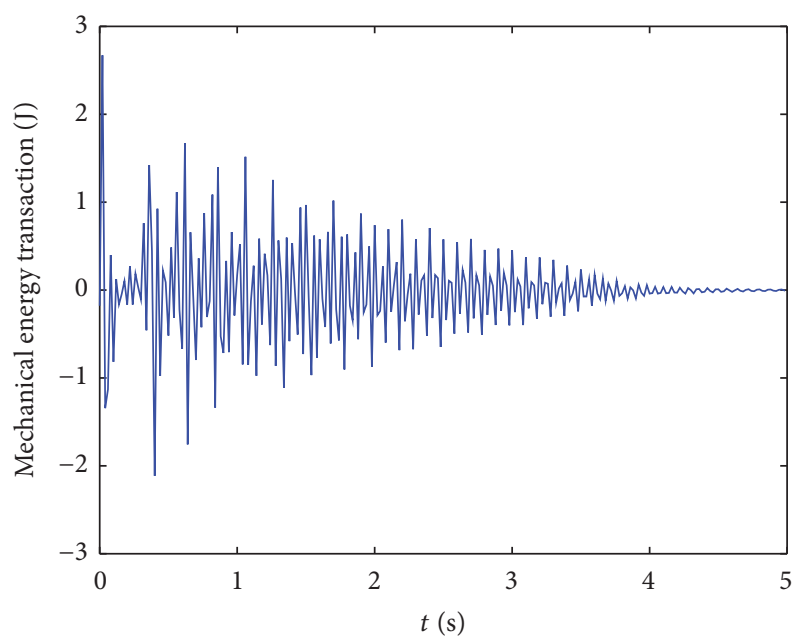

(a)

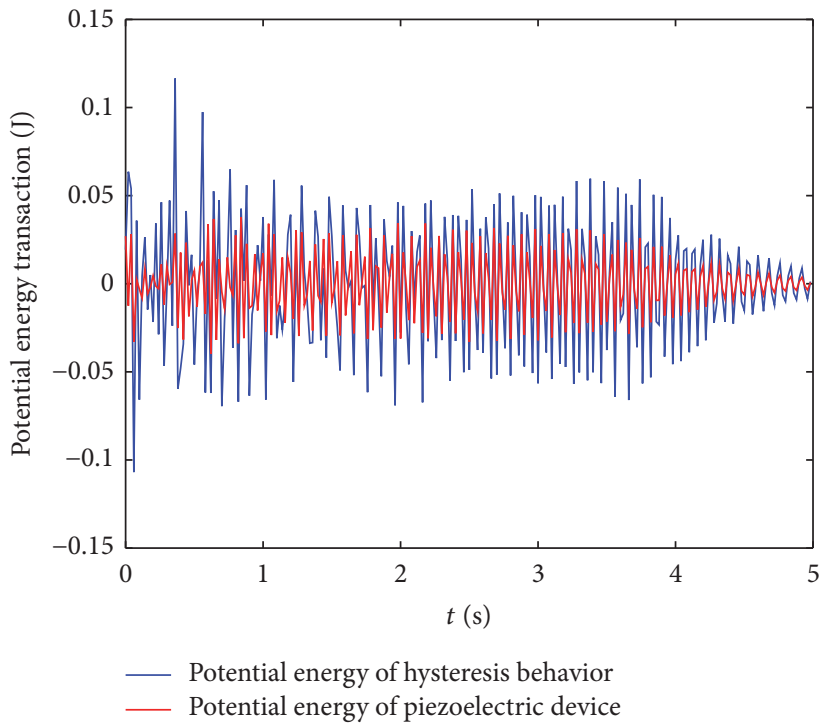

(c)

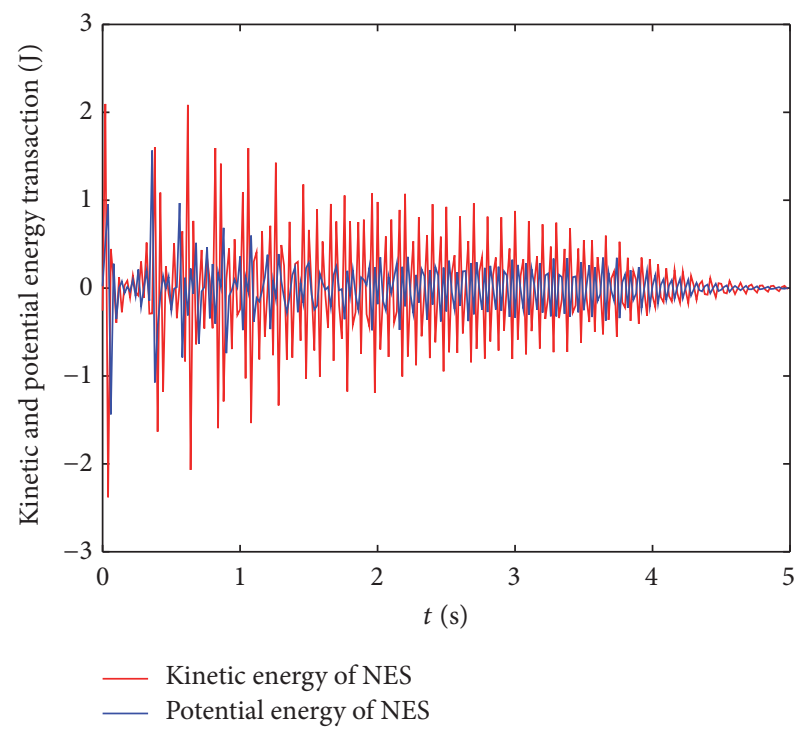

(b)

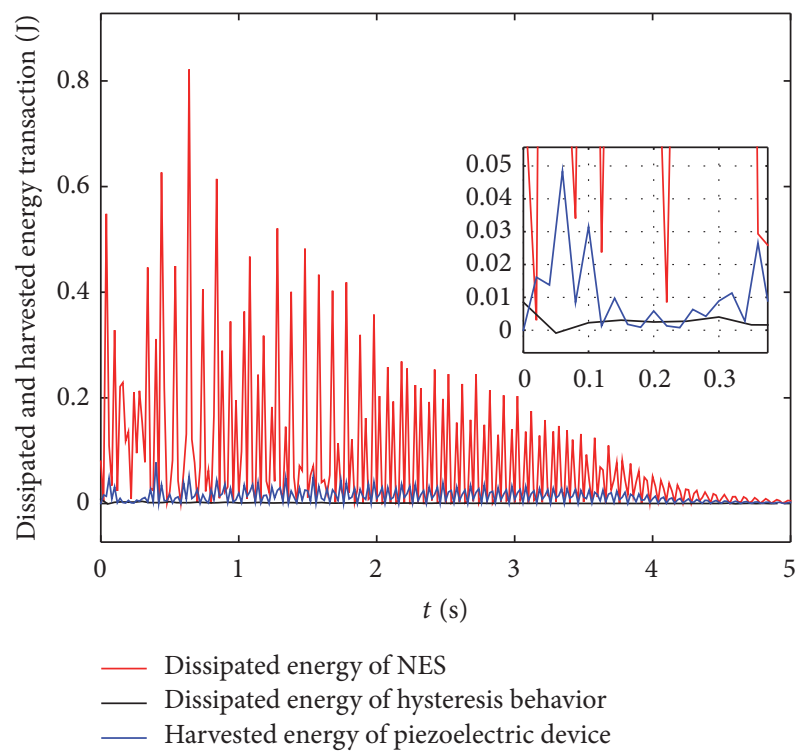

(d)

FIGURE 7: Configuration 1: (a) mechanical energy transaction in the NES-piezoelectricity system; (b) kinetic and potential energy transaction of NES; (c) potential energy transaction of hysteresis behavior and piezoelectric device; (d) dissipated and harvested energy transaction in the NES-piezoelectricity system.

the NES-piezoelectricity system to the primary system. For configuration 1, Figure $7(\mathrm{a})$ presents the mechanical energy transaction in the NES-piezoelectricity system, equal $\Delta E_{\text {kinetic,NES }}+\Delta E_{\text {potential,NES }}+\Delta E_{\text {potential,hysteretic }}+$ $\Delta E_{\text {potential,piezo }}$. Figure $7(\mathrm{~b})$ depicts the kinetic and potential energy transactions of NES, namely, $\Delta E_{\text {kinetic,NES }}$ and $\Delta E_{\text {potential,NES }}$, respectively. Figure 7 (c) illustrates the potential energy transaction of the hysteresis behavior and piezoelectric device, namely, $\Delta E_{\text {potential,hysteretic }}$ and $\Delta E_{\text {potential,piezo }}$, respectively. Figure $7(\mathrm{~d})$ depicts the dissipated and harvested energy transactions in the NES-piezoelectricity system, namely, $\Delta E_{\text {damp,NES }}, \Delta E_{\text {dissipation,hysteretic }}$, and $\Delta E_{\text {harvest,piezo }}$.
For configuration 2, Figure 8(a) presents the mechanical energy transaction in the NES-piezoelectricity system. Figure 8(b) depicts the kinetic and potential energy transaction of NES. Figure 8(c) illustrates the potential energy transaction of the hysteresis behavior and piezoelectric device. Figure $8(\mathrm{~d})$ depicts the dissipated and harvested energy transactions in the NES-piezoelectricity system. Figures 7 and 8 illustrate that the energy in the primary structure and NESpiezoelectricity system is flowing back and forth, highlighting that the dissipated and harvested energy transaction between the primary structure and NES-piezoelectricity system is positive and the instantaneous transaction of mechanical 


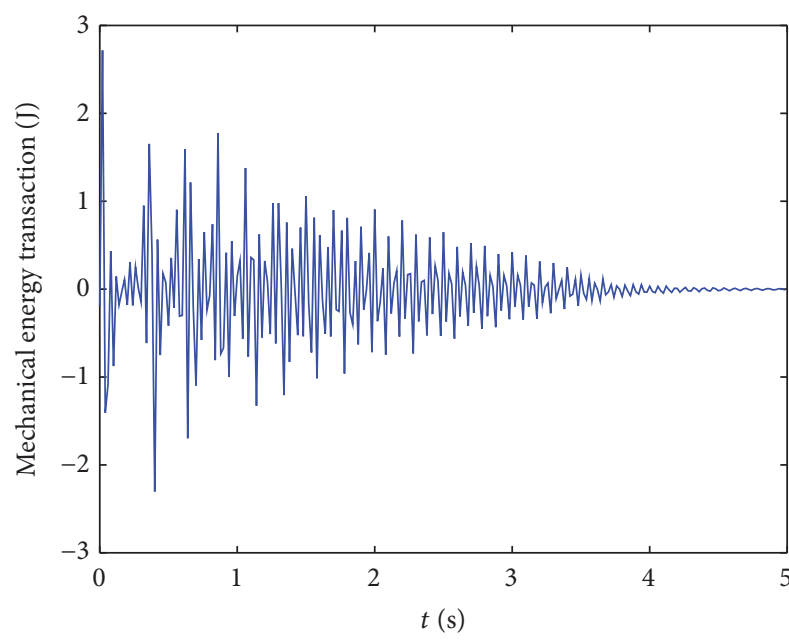

(a)

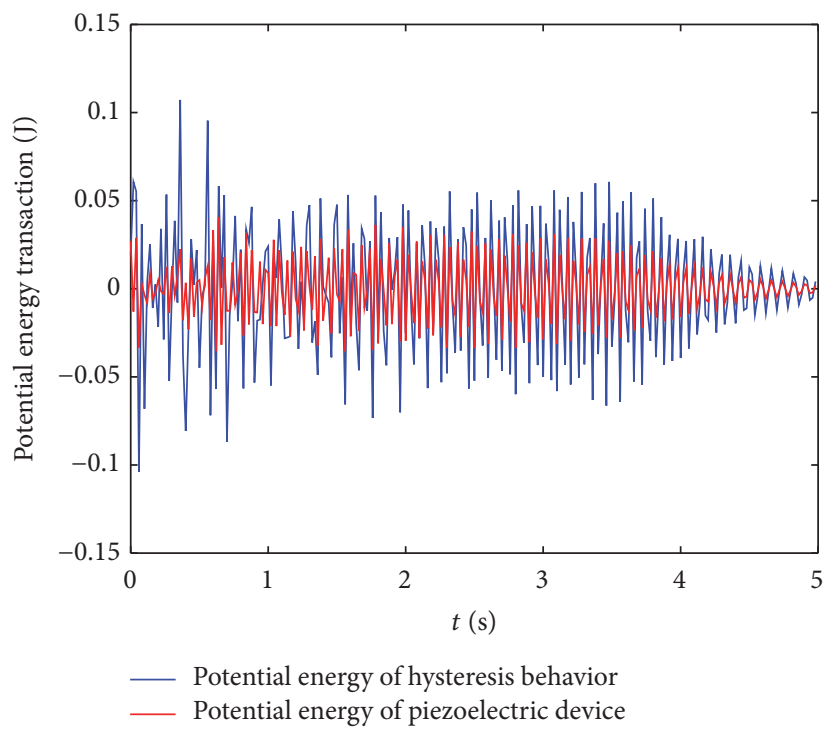

(c)

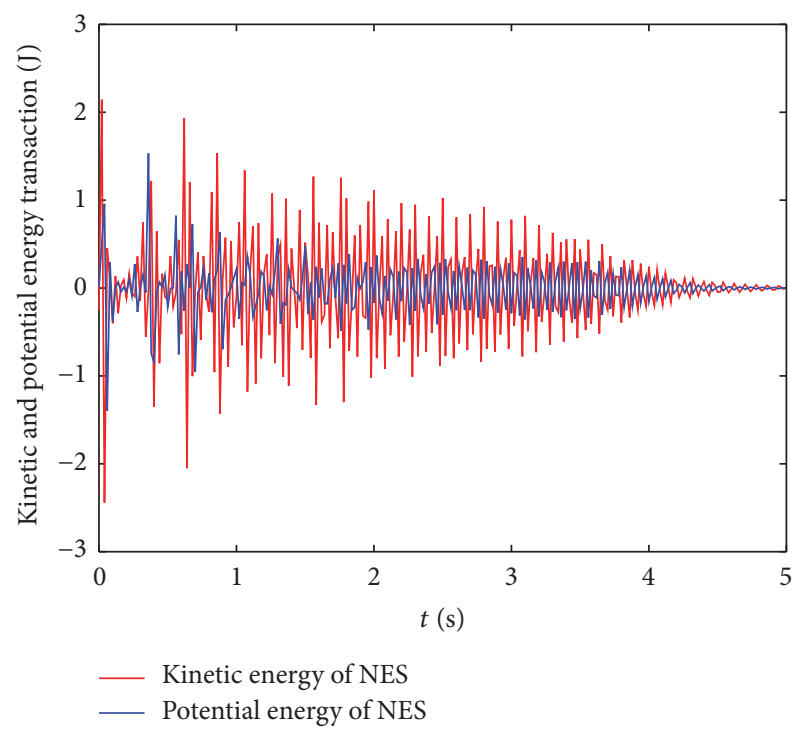

(b)

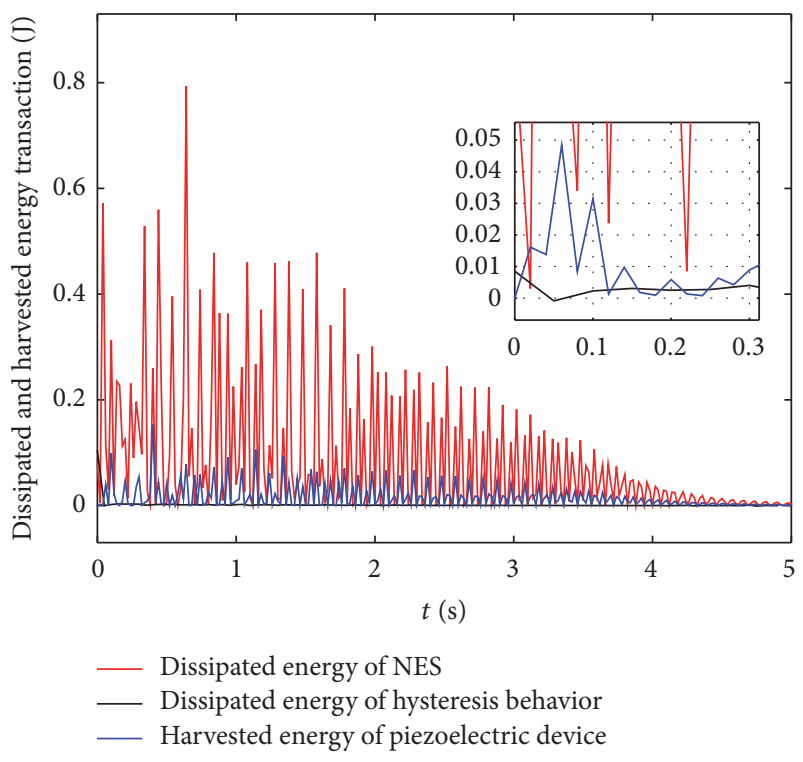

(d)

FIGURE 8: Configuration 1: (a) mechanical energy transaction in the NES-piezoelectricity system; (b) kinetic and potential energy transaction of NES; (c) potential energy transaction of hysteresis behavior and piezoelectric device; (d) dissipated and harvested energy transaction in the NES-piezoelectricity system.

energy between them is more significant than that of dissipated and harvested energy in both configurations.

Comparison of the transient response (the displacement of $M$ ) of the primary system with and without NESpiezoelectricity system in both configuration 1 and configuration 2 indicates that the system can contribute to vibration control. For the two configurations, the process and effect of vibration control are similar, the amplitude of $M$ with NES-piezoelectricity system is little bigger than that without it in the first 2 seconds approximately, and after that the amplitude of $M$ with NES-piezoelectricity system rapidly becomes much smaller than that without the system.
The response of primary structure with NES-piezoelectricity system approaches 0 at 4 seconds (Figure 9).

\section{Conclusions}

This study investigated a novel design for a system integrating NES including hysteresis behavior and an essential, strongly cubic, nonlinear stiffness with a piezoelectric-based vibration energy harvester under shock excitation to realize vibration mitigation and energy harvesting. Two piezoelectric device configurations, including the piezoelectric element embedded between the NES mass and the structure or ground, 


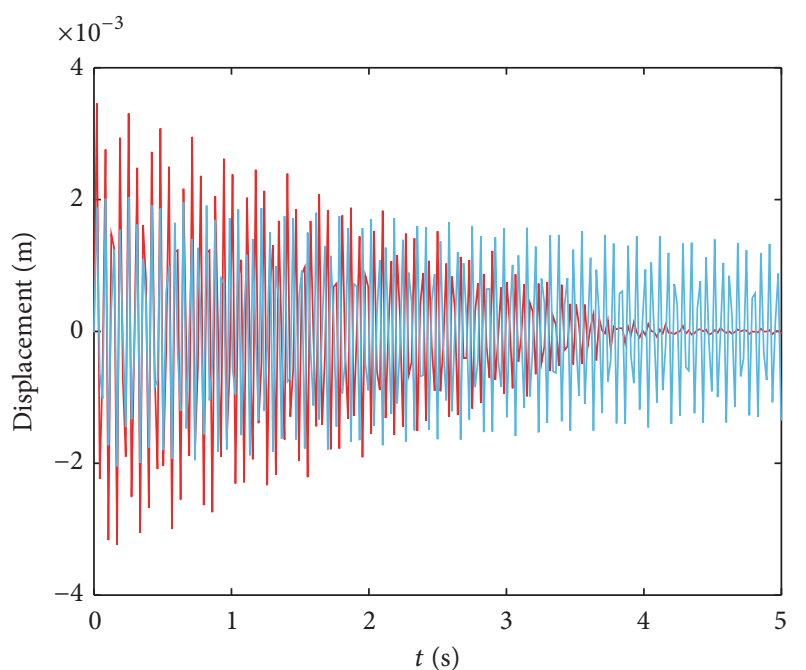

With NES-piezoelectricity Without NES-piezoelectricity

(a)

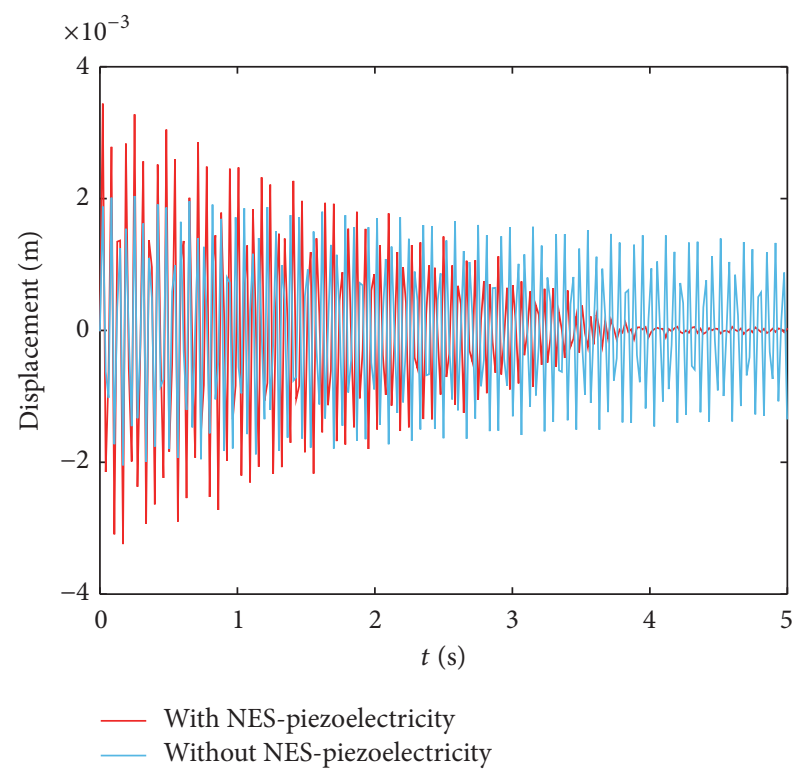

(b)

FIGURE 9: Comparing the transient response of the primary system with NES-piezoelectricity system and without it of (a) configuration 1 and (b) configuration 2 .

were studied through a similar numerical research method. Initially, a big part of shock energy was captured by the NESpiezoelectricity system in the form of mechanical energy. Over time, the captured shock energy was dissipated by the NES damper and the hysteresis behavior of the Bouc-Wen model and harvested by the piezoelectric device. Finally, more than half of the input energy is dissipated by the damper of NES while the energy harvested by the piezoelectric element and dissipated by hysteresis behavior is relatively small. The dissipated and harvested energy by NES-piezoelectric system of the two configurations is slightly different. ETM was applied to examine the instantaneous energy transaction between the primary and NES-piezoelectricity system. The instantaneous transaction of mechanical energy in the NESpiezoelectricity system was more significant than that of dissipated and harvested energy. The NES-piezoelectricity system could realize vibration control of the primary structure and its displacement approaches to zero rapidly in both configurations.

\section{Conflicts of Interest}

The authors declare that they have no conflicts of interest.

\section{Acknowledgments}

This work is supported by the National Natural Science Foundation of China (Project nos. 11402151, 11572182, 51305421, and 11232009). The authors acknowledge the funding support of the Natural Science Foundation of Liaoning Province (Project no. 2015020106) and State Key Laboratory of Structural Analysis for Industrial Equipment Foundation of China (GZ15209).

\section{References}

[1] A. F. Vakakis, "Shock isolation through the use of nonlinear energy sinks," Journal of Vibration and Control, vol. 9, no. 1-2, pp. 79-93, 2003.

[2] M. Kani, S. E. Khadem, M. H. Pashaei, and M. Dardel, "Vibration control of a nonlinear beam with a nonlinear energy sink," Nonlinear Dynamics, vol. 83, no. 1, pp. 1-22, 2016.

[3] O. V. Gendelman, "Transition of energy to a nonlinear localized mode in a highly asymmetric system of two oscillators," Nonlinear Dynamics, vol. 25, no. 1-3, pp. 237-253, 2001.

[4] A. F. Vakakis, O. V. Gendelman, L. A. Bergman, D. M. McFarland, G. Kerschen, and Y. S. Lee, Nonlinear Trageted Energy Transfer in Mechanical and Structural Systems, Springer, Berlin, Germany, 2008.

[5] Y.-W. Zhang, J. Zang, T.-Z. Yang, B. Fang, and X. Wen, "Vibration suppression of an axially moving string with transverse wind loadings by a nonlinear energy sink," Mathematical Problems in Engineering, vol. 2013, Article ID 348042, 7 pages, 2013.

[6] Y. Starosvetsky and O. V. Gendelman, "Interaction of nonlinear energy sink with a two degrees of freedom linear system: internal resonance," Journal of Sound and Vibration, vol. 329, no. 10, pp. 1836-1852, 2010.

[7] T.-Z. Yang, X.-D. Yang, Y. Li, and B. Fang, "Passive and adaptive vibration suppression of pipes conveying fluid with variable velocity," Journal of Vibration and Control, vol. 20, no. 9, pp. 1293-1300, 2014.

[8] A. Luongo and D. Zulli, "Dynamic analysis of externally excited NES-controlled systems via a mixed Multiple Scale/Harmonic Balance algorithm," Nonlinear Dynamics, vol. 70, no. 3, pp. 2049-2061, 2012.

[9] Y. Zhang, J.-R. Zhang, and S.-J. Xu, "Influence of flexible solar arrays on vibration isolation platform of control moment 
gyroscopes," Acta Mechanica Sinica, vol. 28, no. 5, pp. 1479-1487, 2012.

[10] Z. Fang, Y. Zhang, X. Li, H. Ding, and L. Chen, "Integration of a nonlinear energy sink and a giant magnetostrictive energy harvester," Journal of Sound and Vibration, vol. 391, pp. 35-49, 2017.

[11] N. Ebrahimzade, M. Dardel, and R. Shafaghat, "Performance comparison of linear and nonlinear vibration absorbers in aeroelastic characteristics of a wing model," Nonlinear Dynamics, vol. 86, no. 2, pp. 1075-1094, 2016.

[12] H. A. Sodano, D. J. Inman, and G. Park, "A review of power harvesting from vibration using piezoelectric materials," Shock and Vibration Digest, vol. 36, no. 3, pp. 197-205, 2004.

[13] E. Jacquelin, S. Adhikari, and M. I. Friswell, "A piezoelectric device for impact energy harvesting," Smart Materials and Structures, vol. 20, no. 10, pp. 1-12, 2011.

[14] J. M. Renno, J. R. Farmer, and D. J. Inman, "Effects of system parameters and damping on an optimal vibration-based energy harvester," in Proceedings of the AIAA/ASME/ASCE/AHS/ASC Structures, Structural Dynamics, and Materials Conference, vol. 4, AIAA, 2007, 2007-2361.

[15] Z. N. Ahmadabadi and S. E. Khadem, "Nonlinear vibration control and energy harvesting of a beam using a nonlinear energy sink and a piezoelectric device," Journal of Sound and Vibration, vol. 333, no. 19, pp. 4444-4457, 2014.

[16] Y. Zhang, L. Tang, and K. Liu, "Piezoelectric energy harvesting with a nonlinear energy sink," Journal of Intelligent Material Systems and Structures, vol. 28, no. 3, pp. 307-322, 2017.

[17] J. Awrejcewicz, L. Dzyubak, and C.-H. Lamarque, "Modelling of hysteresis using Masing-Bouc-Wen's framework and search of conditions for the chaotic responses," Communications in Nonlinear Science and Numerical Simulation, vol. 13, no. 5, pp. 939-958, 2008.

[18] R. Bouc, "Forced vibration of mechanical systems with hysteresis," in Proceedings of the 4th Conference on Nonlinear Oscillations, Prague, Czech Republic, 1967.

[19] Y. K. Wen, "Method for random vibration of hysteresis systems," ASCE Journal of Engineering Mechanics, vol. 102, no. 2, pp. 249263, 1976.

[20] F. Ikhouane, J. E. Hurtado, and J. Rodellar, "Variation of the hysteresis loop with the Bouc-Wen model parameters," Nonlinear Dynamics, vol. 48, no. 4, pp. 361-380, 2007.

[21] A. E. Charalampakis, "The response and dissipated energy of Bouc-Wen hysteretic model revisited," Archive of Applied Mechanics, vol. 85, no. 9-10, pp. 1209-1223, 2015.

[22] C.-H. Lamarque and A. T. Savadkoohi, "Dynamical behavior of a Bouc-Wen type oscillator coupled to a nonlinear energy sink," Meccanica, vol. 49, no. 8, pp. 1917-1928, 2014.

[23] A. T. Savadkoohi, C.-H. Lamarque, and M. V. Contessa, "Trapping vibratory energy of main linear structures by coupling light systems with geometrical and material non-linearities," International Journal of Non-Linear Mechanics, vol. 80, pp. 3-13, 2016.

[24] L. Q. Chen and T. C. Yuan, "Nonlinear oscillation of a circular plate energy harvester," in Proceedings of the 26th International Congress of Theoretical and Applied Mechanics, Montrèal, Canada, August 2016.

[25] H.-G. Li and G. Meng, "Nonlinear dynamics of a SDOF oscillator with Bouc-Wen hysteresis," Chaos, Solitons and Fractals, vol. 34, no. 2, pp. 337-343, 2007.
[26] H. Ding and J. W. Zu, "Effect of one-way clutch on the nonlinear vibration of belt-drive systems with a continuous belt model," Journal of Sound and Vibration, vol. 332, no. 24, pp. 6472-6487, 2013.

[27] H. Ding and J. W. Zu, "Steady-state responses of pulley-belt systems with a one-way clutch and belt bending stiffness," Journal of Vibration and Acoustics, Transactions of the ASME, vol. 136, no. 4, Article ID 041006, 2014

[28] F. Georgiades, A. F. Vakakis, and G. Kerschen, "Broadband passive targeted energy pumping from a linear dispersive rod to a lightweight essentially non-linear end attachment," International Journal of Non-Linear Mechanics, vol. 42, no. 5, pp. 773-788, 2007. 


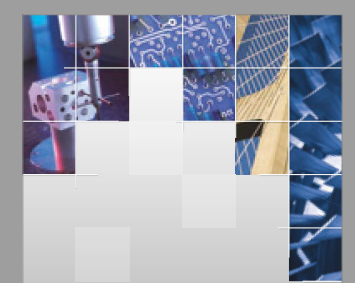

\section{Enfincering}
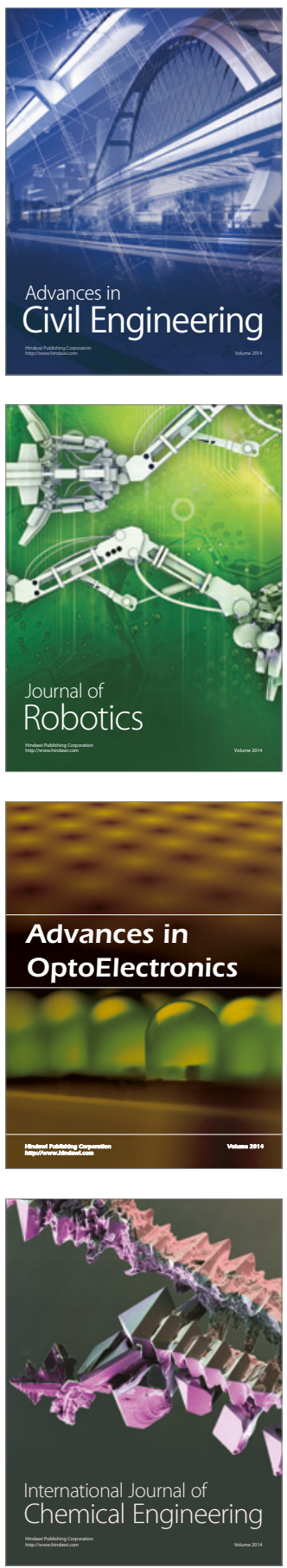

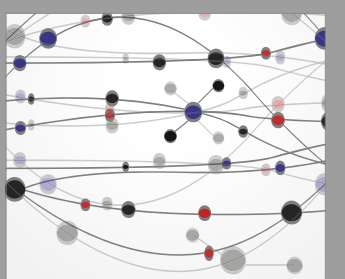

The Scientific World Journal

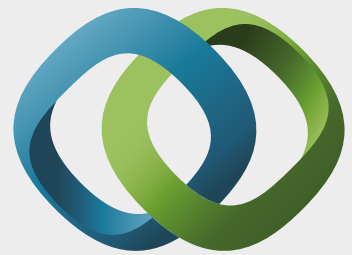

\section{Hindawi}

Submit your manuscripts at

https://www.hindawi.com
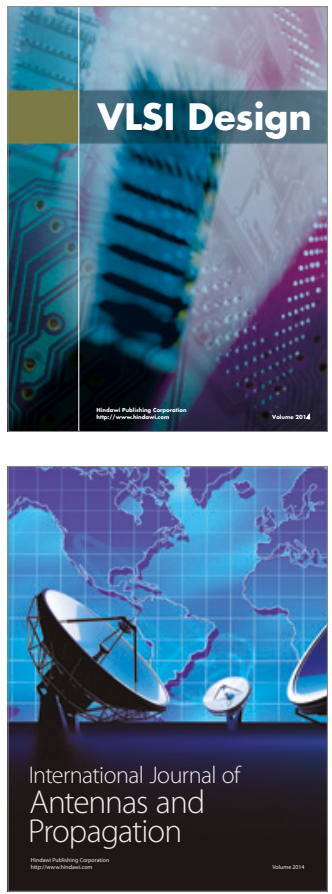

\section{Rotating}

Machinery
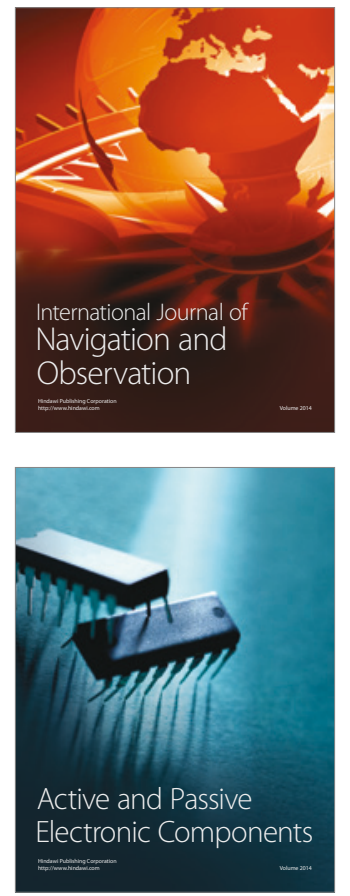
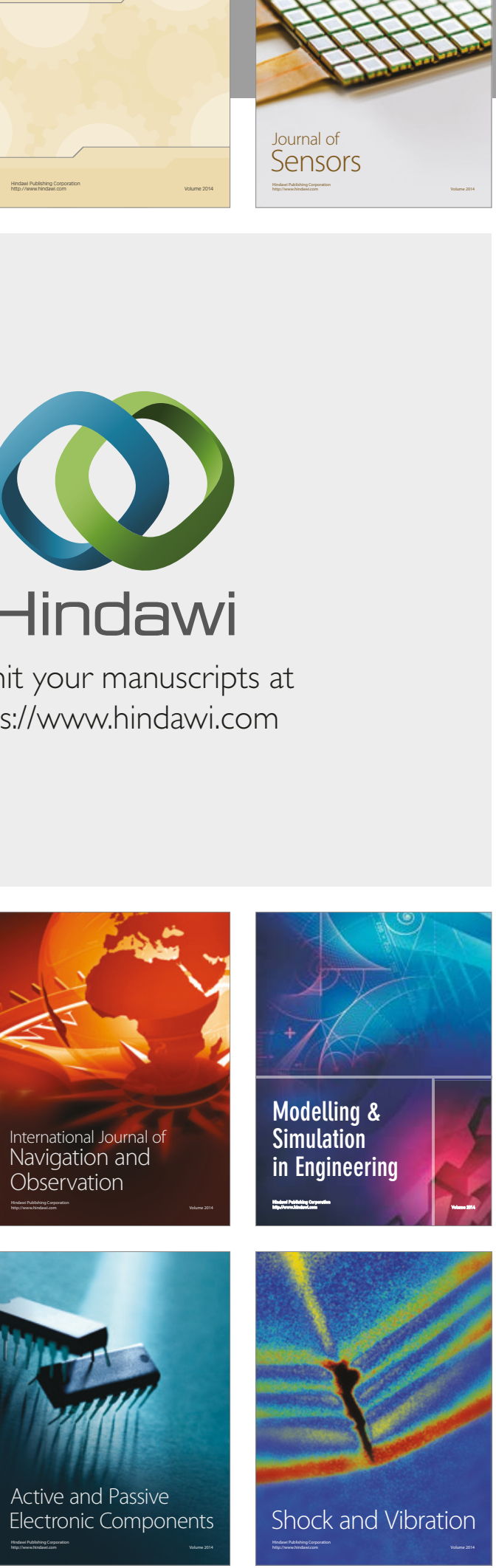
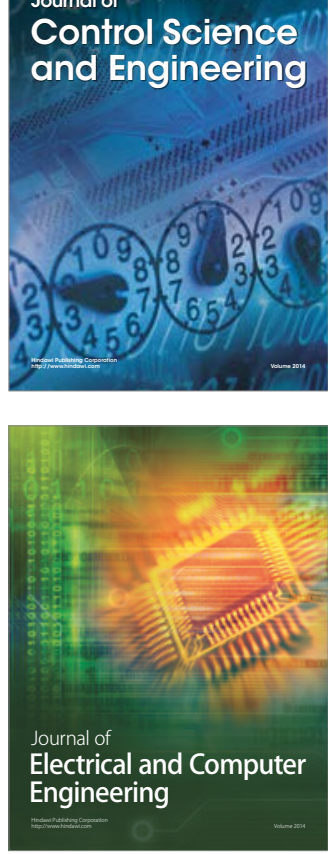

Distributed

Journal of

Control Science

and Engineering
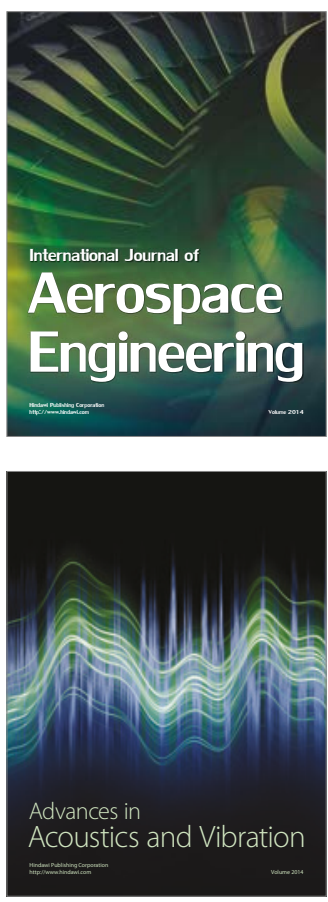

Sensor Networks 